I should have known exactly what he meant, and made bold to differ from him.

I feel sure, however, that those geologists who have endeavoured to revise the almost forgotten teaching of Hutton as to the important part played by stilaërial denuding forces in forming the present surface of the ground, are by no means forgetful of the obligations they are under to upheaval for furnishing them with materials to be shaped ; and in cases of great mountain chains they have always admitter that the superior elevation of the ground is mainly due to internal action, though they hold that all the sculpturing of the upheaved mass into gorge and peak is due to atmospheric agency.

79, Dodworth Road, Barnsley, Sept. 3

\section{Geology of Devonshire}

A RAILWAY of eight or ten miles is now in course of construction between Totnes and Ashburton in Devonshire. To a geologist the cuttings near the latter town are most interesting. I am not a geologist, although the science is deeply interesting to me. I returned from Ashburton ten days ago. The rocks there at one part of the line were evidently volcanic. They appear exactly as if they had been melted, and in boiling up a scum or froth had risen on the surface, and in cooling had left air-bubbles, now nearly filled with sometimes yellowish crystals. The rock is very hard, and has a stratum of what was once slate, ten or twelve feet thick, and as the workmen work it out it bears the colour which great fire would give it. As blocks of the otller rock are torn out by powder, they are found to contain or enclose fragments several inches square of the superincumbent slate rock, too hard to be melted. This rock is not stratified, but breaks into any form. A few hundred yards off they are working through ironstone as hard as iron itself. The heavy sledge hammer rings on the blocks as on an anvil. At the east end of the town are two pits worked for umber, indeed there are several fields of which the soil a few inches below the surface consists wholly of umber. I do not expect there is any one in the neighbcurhood who fecls an interest in geology. I saw a letter in NATURE on a geological sulject from Mr. Pengelly, of Torqua y and I wrote him on the above subject. I have no doubt the line is very interesting in the other parts, as the rocks greatly vary thereabouts.

A learned geologist would have made what I have attempted to describe more interesting. He would find much to employ him in that neighbourhood. W. LUSCOMEE

\section{Hereditary Deformities}

In the lessons in Ethnology in "Cassell's Popular Educator," it is stated, on the authority of Dr. Theodor Waitz, and the Secretary of the Anthropological Society, that "an officer, whose little finger had accidentally been cut across, and had, in consequence, become crooked, transmitted the same defect to his offspring. Another officer wounded at the battle of Eylau, had his scar reproduced on the foreheads of his children." And again, "In Carolina, a dog which had accidentally lost its tail transmitted the defect to its descendants for three or four generations." Do these stories rest on a good foundation? We know that congenital peculiarities of form and disposition are transmitted from parent to offspring, but that an accidental deformity should be so transmitted is a very different affair, and if substantiated would introduce Accidenial Distortion as a co-worker with natural selection in the modification of species.

Faversham, Kent, Aug. 27

WM. FIELD

\section{Poisoning by Enanthe crocata}

PERMit me to send you the following notes with regard to the case of poisoning by Enanthe crocata which appeared in your issues of I8th August and Ist September.

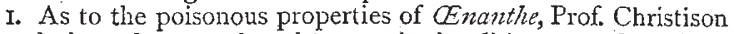
found that plants gathered in certain localities were harmless, while others from different places were highly poisonous.

II. As to the mode of deatk. 'This seems materially to differ from that observed and recorded with regard to poisoning with hemlock (Conium maculatum). In the case of poisoning with hemlock which took place in 1 rlinlurgh in 1845 (recorded in the Edin. Med. and Szurg. Fournal, No. 164, and also Prof. Bemnett's "Principles and Practices of Medicine") the mind remained clear till the end, and death resulted from asphyxia produced by slow paralysis of the muscles of respiration. The muscular paralysis commenced in the feet.

In the recent case of poisoning by (Enanthe there seems to have been coma and convulsion for half an hour previous to death; no paralysis seems to have occurred over the body. From the account of the hemlock case to which I have referred, that plant also seems not to have any particularly acrid taste. The part that seems strange to me is the difference in the mode of death with plants so nearly allied to each other as the CEnanthe and the Conizin. J. W. E., EDIN.

\section{NOTE ON SOME INSTANCES OF PROTECTIVE ADAPTATION IN MARINE ANIMALS}

$7 \mathrm{HE}$ various phenomena of mimicry and protective adaptation have recently received much attention, notably from Messrs. Darwin, Bates, and Wallace, and some very interesting facts and reasonings on the subiect are contained in the recently published "Contributions to the Theory of Natural Selection" by the last-named author. It can scarcely be needful to explain at much length the nature of the phenomena in question. Well-marked instances of mimicry are not very common; some of the most surprising are those of the leaf and stick insects of the Tropics, which it is almost absolutely impossible, when at rest, to distinguish from dead leaves and twigs. The importance of these resemblances, in conferring protection from attack, will be at once evident. Commoner instances of adaptation, which may indeed be noticed wherever we turn our eyes upon the animal creation, are those of more or less complete resemblance of colour between the animal and its surroundings. The most remarkable instance of this kind which has come under my own observation is perhaps that of the caterpillar of the Emperor moth (Saturnia pavonia minor), which, with its green ground and brilliant pink spots, is almost undistinguishable from the heather upon which it frequently feeds.

Numerous instances of this kind amongst terrestrial animals might be brought forward, but less attention has been paid to similar points in the less highly-organised of marine animals. They are, for the most part, much less easily observed in their natural haunts, and their habits and the dangers to which they are cxposed are of necessity imperfectly understood. We may note, however, that fishes very commonly assume the colours of surrounding objects; the flounder is almost exactly of the colour of the sand on which it lies, and fishes which bask amongst groves of seaweeds are often of brilliant and variegated colours corresponding very much with the vegetation around them.

The two instances which form the subject of this notice came under my observation while dredging in June last in the Frith of Clyde. In one spot the dredges brought up many plants of Laminarice with their roots, wbich consist of a conical mass of contorted and intertwined fibres about a line or two in diameter; amongst these were imbedded quantities of nulliporesa calcareous seaweed of the genus Melobesia- $(M$. calcarea). The larger weed had, in fact, grown in a bed of the nullipore, which came up abundantly in the dredge, and indeed now forms on a closely adjacent part of the coast a raised beach of several feet in thickness. Amongst the nullipore which. matted together the laminaria roots were living numerous small starfishes (Ophioconia bellis) which, except when their writhing movements betrayed them, were quite undistinguishable from the calcareous branches of the Alga; their rigid, angularly-twisted rays had all the appearance of the coralline, and exactly assimilated to its deep purple colour, so that though I held in my hand a root in which were half a dozen of the starfishes, $I$ was really unable to detect them until revealed by their movements. 
The second instance is that of a shelifish, Lima hians. This beautiful moliusc is well known f:equently to construct for itself a nest-a long tube lined with byssal fibres and covered extcrnally, aiter the manner of a caddis-worm, with nullipores, stones, old shells, or probably any material which lies conveniently at hand. We may perhaps account for a habit so different from that of other mollusca by the following considerations :-

The animal is an exceedingly showy one, more so than almost any other British mollusc, having two valves of snowy white, from betwcen which are protruded long tentacular fringes of a brilliant orange or vermilion hue; when alarmed, it darts, or almost, as one might say, flies, in a fitful manner through the water, showing its gorgcous colours very conspicuously - so that indeed in the Channel Islands it has acquired the name of "Angel's Wings." Other mollusca, such as some of the Pectens, are brilliantly co'oured, and live without the protection of any nest, but their shells are very strong and close firmly, so that they could not easily be masticated by crdinary fishes. The shell of the Lima, on the contrary, is very fragile, and would easily be dealt with by fishes which are accustomed to devour wholesale crabs and other hardbodied creatures. It is, therefore, easy to believe that the two characters of tenderness and brilliant colouring would speedily ensure the extinction of the species were it not protected in some extraordinary manner such as that of the concealment aiforded by a nest. Mr. Wallace has shown, in a very interesting manner, how birds of brilliart plumage build nests of a character adapted for concealment during incubation, and it seems to me that the similar habit of the Lima may probably be referred to the same cause.

Grorge S. BRADY

\section{SWALLOWS' NESTS*}

A FEW months ago $M$. Pouchet published an article on the subject of swallows' nests, which seemed destined to modify all our previous ideas of reason and instinct. According to this naturalist, the common swallow had modified his habits, and had made certain progress in the art of nest-building.

Had this theory been correct, we must have renounced our preconceived notions which place an insuperable barrier between reason and instinct. If we assume instinct to be a faculty incapable of development, and not progressive in the animal, it is clear that if any modification or progress were once scientifically proved to have taken place in the arts of which each animal is capable, it would be necessary henceforward to classify such arts as appertaining to the domain of reason.

The communication, therefore, made by M. Pouchet to the Académie des Sciences would have had great weight had the facts which it related been confirmed by subsequent observation.

Such, however, does not seem to be the case, for $M$. J. B. Noulet has recently pointed out the error contained in M. Pouchet's statement.

According to M. Noulet, there are two distinct varieties of swallows, the window swallow (Hirundo urbica, of Linnæus), and the chimney swallow (Hirundo mustica).

These two types do not intermingle, and have somewhat different habits; for instance, the chimney swallow is always the first to arrive and the first to leave these countries. Their nests are also different, and the difference is so well marked that there need be no difficulty in deciding as to the builders who have constructed them.

The city swallows (H. urbica) always choose the lofty situation, and group their nests in continuous lines, sometimes double and even triple. The H. rustica, on the other hand, establishes itself lower down, and constructs its nest apart from its fellows. The nests, too, of the first-named $x$ " Nos deux hirondelles et leurs nids." Par J. B. Noulet. valiety are chiefly distinguishable by a greater depth, and by a circular aperture just large cnough to allow the bird to go in and out without dificulty.

M. Pouchet, paying no attention to the differcnce existing bctween the two varieties to which we have alluded, takes the nests of the city swallow for those of this rustic sister brought to a higher degree of perfection.

This, at least, is M. Noulet's opinion. It remains to be seen if $M$. Pouchet will accept the explanation, or whether he will be prepared to defend his own theory. In either case the readers of this journal shall be informed.

ALFRED NAQUET

\section{FACULTY OF SCIENCE IN UNIVERSITY COLLEGE}

SOME months ago it was announced in our columns that a Faculty of Science had been formed in University College. In the prospectus now issued for the forthcoming session there appears the following general statement:-

"The Faculty of Science has been instituted to bring into full light the actual extent of the scientific teaching in University College, and to meet, consistentiy with sound educational principles, the growing demand for instruction in science.

"The Faculty of Arts in University College, instituted to give a general training in literature and science, such as is required for a degree in arts in the University of London, not only has from the first contained chairs in which the scientific instruction has been developed far beyond the needs of arts-students, but by a steady process of growth has come to include others bearing no relation to an arts-curriculum. So considerable is the scientific staff now actively at work in the college, that the authorities believe the time has arrived when the science-teaching carried on within its walls may assume all the character of independence and dignity associated with the academic title of Faculty.

"The demand for instruction in science and the recognition of science in education are facts beyond question. In University College itself the number of students seeking a broad scientific training or pursuing special scientitic studies has gone on steadily increasing; while in the University of London and elsewhere, degrees in science, both general and special, have been conferred for some years past. The importance, also, of science as a preparation for industrial pursuits is now generally acknowledged, as appears in the efforts that have been made of late years to supply scientific instruction in socalled technical schools.

"The main principle represented by the new Faculty is, that science should first of all be cultivated for its own sake, and that even where there is a practical object in view, a broad foundation should be laid of general scientific training. It is believed that the habits of thought thus engendered are the first conditions of all true advance, either in scientific discovery or in practical invention. A second principle is, that the pursuit of science should not be divorced from literary culture; and this the Faculty, from its position in University College, is specially enabled to uphold. As regards the interpretation of the word Science, it only remains to add that this is taken in no narrow sense. Certain subjects are included which lie out of the sphere of Natural Science, as commonly understood, but none that do not admit of a strictly scientific treatment."

As at present constituted, the Faculty includes chairs of pure mathematics, applied mathematics and mechanics, physics, chemistry, and practical chemistry, mineralogy and geology, engineering, architecture and construction, botany, comparative anatomy and zoology, pnysiology, practical physiology and histology, philosophy of mind and logic, political economy. 